\title{
Plasma SGIP1 methylation in diagnosis and prognosis prediction in hepatocellular carcinoma
}

\author{
Guo-Feng XIE ${ }^{1,2, *}$, Yu-Xia XU ${ }^{2, *}$, Fei XU ${ }^{1,2}$, Li-Yue SUN ${ }^{1,2}$, Zu-Lu YE ${ }^{1,2}$, Jiang-Jun MA ${ }^{1,2}$, Hai-Yun WANG ${ }^{1,2,3, *}$, Jian-Yong SHAO ${ }^{1,2, *}$ \\ ${ }^{1}$ State Key Laboratory of Oncology in South China, Collaborative Innovation Center for Cancer Medicine, Sun Yat-sen University Cancer Cen- \\ ter, Guangzhou, 510060, China; ' 2 Department of Molecular Diagnostics, Sun Yat-sen University Cancer Center, Guangzhou, 510060, China; \\ ${ }^{3}$ Guangzhou Institute of Pediatrics, Guangdong Provincial Key Laboratory of Research in Structural Birth Defect Disease, Guangzhou Women \\ and Children's Medical Center, Guangzhou Medical University, Guangzhou 510623, Guangdong, China
}

*Correspondence: wanghaiy@sysucc.org.cn; shaojy@sysucc.org.cn

Received June 23, 2020 / Accepted September 7, 2020

\begin{abstract}
Aberrant methylation of some genes can serve as promising biomarkers in hepatocellular carcinoma (HCC). This study aimed to investigate the diagnostic and prognostic value of plasma SGIP1 methylation in HCC. The study included a total of 269 subjects, of which 129 were with HCC, 45 with liver cirrhosis (LC), 45 with chronic hepatitis B (CHB), and 50 were healthy controls (HCs). The aberrant methylation was detected by quantitative methylation-specific polymerase chain reaction (qMSP). The area under the curve (AUC) was 0.872 in distinguishing HCC from HCs, with a sensitivity of $85.3 \%$ and a specificity of $88 \%$. The AUC was 0.728 , when it distinguished HCC from CHB, with a sensitivity of $43.4 \%$ and a specificity of $97.8 \%$. The AUC was 0.728 in distinguishing HCC from LC, with a sensitivity of $43.4 \%$ and a specificity of $97.8 \%$. Elevated levels of SGIP1 methylation in HCC patients showed poorer overall survival (OS), progression-free survival (PFS), and metastasis-free survival (MFS) than those with low levels (Kaplan-Meier method and the log-rank test, p<0.05). SGIP1 methylation in different study groups demonstrated different sensitivities. SGIP1 methylation detection in the plasma may serve as a non-invasive diagnostic and prognostic biomarker for HCC.
\end{abstract}

Key words: SGIP1, methylation, hepatocellular carcinoma, plasma, diagnosis, matrix-assisted laser desorption ionization time-of-flight mass spectrometry

At present, the incidence of malignant tumors is increasing worldwide due to environmental conditions, genetics, and smoking $[1,2]$. China has a high incidence of liver cancer, with more than $50 \%$ of new cases and deaths worldwide occurring in China $[3,4]$. Treatment for liver cancer includes surgical resection, radiofrequency ablation, transcatheter arterial chemoembolization, and targeted therapy [5-8]. The early symptoms for patients with liver cancer are often not obvious, and it is usually diagnosed during the advanced stages of the disease. The treatment efficacy for patients with early-stage liver cancer is much higher compared to patients with advanced-stage $[9,10]$. Hence, early detection and diagnosis are vital for improving the prognosis of patients with liver cancer. Research focusing on early diagnosis has been intensively studied in recent years $[11,12]$.

Alpha-fetoprotein (AFP) is currently the only widely used serum biomarker for HCC [13-15]. However, several studies have demonstrated negative AFP in some HCC [16-18]. This limits its clinical utility to detect all forms of HCC. Hence, the search for a more sensitive non-invasive biomarker is urgently needed. Current studies have demonstrated that the methylation status of tumor-related genes could be used for tumor diagnosis, efficacy observation, and prognosis $[19,20]$. SH3 domain GRB2 like endophilin interacting protein 1 (SGIP1) is an endocytosis protein [21]. SGIP1 is located on chromosome 1p31.3. SGIP1 was reported that it is a neuronal protein that regulates energy balance and plays an important role in clathrin-mediated endocytosis. It has been reported to be involved in the occurrence and development of gastric and intestinal cancers $[22,23]$. Through the Cancer Genome Atlas (TCGA) database (http://ualcan. path.uab.edu/analysis.html), we found that SGIP1 methylation in liver cancer tissue is higher than that in normal liver tissue [24]. Can SGIP1 methylation be used for the diagnosis of liver cancer? At present, no studies have been published with regard to the methylation status of SGIP1 in HCC. Our study investigated the role and methylation status of SGIP1 for liver cancer diagnosis. Matrix-assisted laser desorption ionization time-of-flight mass spectrometry (MALDI-TOF MS) was used to detect SGIP1 methylation status in HCC 
tissues and matched normal tissues. Quantitative methylation-specific PCR was used to detect SGIP1 methylation status from 129 liver cancer patient plasma samples prior to treatment. Forty-five patients with hepatitis B and 45 patients with liver cirrhosis were confirmed to meet the inclusion criteria. Methylation of the SGIP1 gene in the plasma of 50 healthy subjects was also included. The sensitivity, specificity, and accuracy of the ROC curve were used to analyze the value of SGIP1 gene methylation status for the diagnosis of liver cancer. In addition, the clinical characteristics of liver cancer patients i.e., gender, age, AFP, and TNM stage were collected. The correlation between SGIP1 methylation status and clinical characteristics of liver cancer patients were then analyzed.

\section{Patients and methods}

Tissue samples. HCC tissues and matched normal tissues ( $3 \mathrm{~cm}$ from the tumor margin) were collected from $16 \mathrm{HCC}$ patients who were diagnosed and underwent the surgery at the Department of Liver Surgery in Sun Yat-sen University Cancer Center between October 2017 and November 2017. All patients provided written informed consent, which was approved by the Ethics Committee of Sun Yat-sen University Cancer Center. The patients' characteristics are shown in Table 1.

Blood samples. A total of 269 subjects who were admitted to Sun Yat-sen University Cancer Center and the Third Affiliated Hospital of Sun Yat-sen University between October 2017 and August 2018 were enrolled in this study. Of those subjects, 129 were diagnosed with hepatocellular carcinoma, 50 were healthy controls ( $\mathrm{HC}$ ), 45 were diagnosed with liver cirrhosis (LC), 45 were diagnosed with chronic hepatitis B (CHB). It is worth mentioning that patients with LC and $\mathrm{CHB}$ have been excluded from HCC detection by ultrasound, $\mathrm{CT}$, and MRI. Blood samples were obtained from the subject above by phlebotomy using $5 \mathrm{ml}$ EDTA-treated tubes, and the prepared plasma $(2 \mathrm{ml})$ from blood samples within $2 \mathrm{~h}$ of collection by centrifugation ( $1600 \times \mathrm{g}, 10 \mathrm{~min})$, followed by transferring the supernatant into a $2 \mathrm{ml}$ centrifugation tube and subsequent centrifugation $(16000 \times \mathrm{g}, 10 \mathrm{~min})$. Plasma samples were stored at $-80^{\circ} \mathrm{C}$ until analysis. All participants provided written informed consent. This study was approved by the Ethics Committee of Sun Yat-sen University Cancer Center.

Methylated primer design. The full CpG island sequence of the SGIP1 gene was queried on the UCSC website, followed by designing of the primers at the EpiDesigner website.

Tissue DNA extraction and sodium bisulfite modification. After thawing the sample stored at $-80^{\circ} \mathrm{C}$, the DNA was extracted from the tissues by phenol/chloroform and ethanol precipitation according to the manufacturer's protocol. The DNA concentration and purity of the sample were detected by NanoDrop 2000. The total amount of DNA was made up to $\sim 3-5 \mu \mathrm{g}$, and its concentration was greater than $50 \mathrm{ng} / \mu \mathrm{l}$.
The DNA extracted from each specimen was then subjected to bisulfite treatment using the EZ conversion kit (Zymo Research, Orange, CA, USA).

MALDI-TOF MS analysis. MALDI-TOF MS analysis technology combines a base-specific digestion reaction and MALDI-TOF detection principle to realize multiple CpG analysis and detection. The bisulfite-treated DNA was subjected to PCR with specific primer pair. The primers are shown in Table 2. The amplification of $1 \mathrm{ml}$ of bisulfitetreated DNA (20 ng/ml) was carried out using HotStar Taq Polymerase in $5 \mathrm{ml}$ of reaction volume, and using PCR primers at a final concentration of $200 \mathrm{mM}$. After treatment with shrimp alkaline phosphatase, $2 \mathrm{ml}$ of the PCR products were used as a template for in vitro transcription to obtain RNA transcripts. The reverse product was subjected to basespecific cleavage, and the resulting samples were conditioned and spotted on a 384-pad SpectroCHIP. The resultant methylation calls were performed by using EpiTyper software v1.0.

RNA extraction and qRT-PCR. Trizol reagent (Invitrogen, Carlsbad, CA, USA) was used to extract total RNA from HCC tissues and normal tissues according to the manufacturer's protocol. Reverse transcription and qRT-PCR were performed with the Applied Biosystems 7500 RealTime PCR System (ABI7500; Life Technologies, Darmstadt, Germany) using SYBR Green qRT-PCR kit from Takara Biotechnology (Takara, Dalian, China). GAPDH was used as an internal control for the quantification of the mRNA levels of genes. The primers used were synthesized by Ruibo (Ruibo, Guangzhou, Guangdong, China) and are shown in Table 3.

Table 1. The characteristics of tissue samples.

\begin{tabular}{|c|c|c|}
\hline Characteristics & Cases & $(\%)$ \\
\hline Total case number & 16 & \\
\hline \multicolumn{3}{|l|}{ Gender } \\
\hline Male & 15 & 93.8 \\
\hline Female & 1 & 6.2 \\
\hline \multicolumn{3}{|l|}{ Age (years) } \\
\hline$\leq 44$ & 8 & 50 \\
\hline$>44$ & 8 & 50 \\
\hline \multicolumn{3}{|l|}{$\mathrm{T}$} \\
\hline $\mathrm{T} 1+\mathrm{T} 2$ & 7 & 43.8 \\
\hline $\mathrm{T} 3+\mathrm{T} 4$ & 9 & 56.2 \\
\hline \multicolumn{3}{|l|}{$\mathrm{N}$} \\
\hline No & 14 & 87.5 \\
\hline N1 & 2 & 12.5 \\
\hline \multicolumn{3}{|l|}{ Clinical stage } \\
\hline $\mathrm{I}+\mathrm{II}$ & 7 & 43.8 \\
\hline III+IV & 9 & 56.2 \\
\hline \multicolumn{3}{|l|}{$\operatorname{AFP}(\mu \mathrm{g} / \mathrm{l})$} \\
\hline$\geq 25$ & 11 & 68.8 \\
\hline$<25$ & 5 & 31.2 \\
\hline
\end{tabular}

Abbreviations: T-tumor; N-node 
Table 2. MALDI-TOF MS primers of SGIP1.

\begin{tabular}{ll}
\hline Primer name & Primer sequence (5'-3') \\
\hline SGIP1-1 F & TTTAGGTTTTTATTTGGGTGAATGA \\
SGIP1-1 R & CCTCCCACTCCAACCTAAACTC \\
SGIP1-2 F & TTGTTATTTTAATAGGGGATTTTGG \\
SGIP1-2 R & CCACAAACACTAACATTTAAAATTCCT \\
SGIP1-3 F & AGGAATTTTAAATGTTAGTGTTTGTGG \\
SGIP1-3 R & CTACCTACTCCCCTTTCCAACCT \\
SGIP1-4 F & TTTTTTGTTAAGGTGGTAGTTTTTGA \\
SGIP1-4 R & AACCTACATCTCCTAACACAATACCC \\
SGIP1-5 F & TTGTGTTAGGAGATGTAGGTTGGTT \\
SGIP1-5 R & TCCTTAATTTCCAAAAAATCTAAAA
\end{tabular}

Abbreviations: MALDI-TOF MS; Matrix-assisted laser desorption ionization time-of-flight mass spectrometry

Table 3. PCR primers of SGIP1 mRNA and quantitative methylationspecific SGIP1 PCR primers

\begin{tabular}{ll}
\hline Primer name & Primer sequence (5'-3') for SGIP1 mRNA \\
\hline SGIP1-1 F & CAAGAACCACTGTCCCAAGA \\
SGIP1-1 R & TGTGGTGAAGCTCTGTTCAT \\
GAPDH F & GGGAAACTGTGGCGTGAT \\
GAPDH R & GAGTGGGTGTCGCTGTTGA \\
& Methylation-specific primers (5'-3') and TaqMan probes \\
SGIP1-1 F & GCCTTTGGAATACGGAAGAAAGA \\
SGIP1-1 R & TGCTATTGTAGGGTGGTTCGT \\
SGIP1-1 FAM & GCGCGTCGCGGAGAAACGTGTT \\
GAPDH F & TACTAGCGGTTTTACGGGCG \\
GAPDH R & TCGAACAGGAGGAGCAGAGAGCGA \\
GAPDH VIC & GAGAAGTTGAGTTATGGGTAGTTGGAAAAGGA \\
\hline
\end{tabular}

Immunohistochemistry (IHC). IHC was performed to examine the SGIP1 expression in human HCC specimens. Briefly, the tissue sections were fixed using $4 \%$ formaldehyde overnight and then embedded in paraffin. After deparaffinization and hydration, the sections were pretreated with sodium citrate buffer in a microwave for antigen retrieval and blocked using normal goat serum. The sections were then stained using rabbit anti-SGIP1 antibodies (Abcam, USA) overnight at $4{ }^{\circ} \mathrm{C}$, and then incubated in biotinylated goat anti-rabbit IgG secondary antibodies for $1 \mathrm{~h}$. Finally, the sections were stained with an avidin-biotin peroxidase complex (GeneTex, USA). The section scoring was performed by two independent pathologists who were blinded to patient data of the samples. The immunostaining was scored according to the German immunoreacted score [25]. Scores representing percentage of tumor cells positively stained were $0(<5 \%), 1(5-25 \%), 2(25-50 \%), 3(50-75 \%)$, or $4(>75 \%)$. The score standards for the staining intensity were 0 (negative), 1 (weak), 2 (medium), and 3 (strong). The total score of $\geq 4$ was defined as the high-expression group.

Plasma DNA extraction and sodium bisulfite modification. The plasma DNA was extracted from $2 \mathrm{ml}$ of plasma samples using the QIA amp DNA Blood Mini Kit (Qiagen, Hilden, Germany). DNA extracted from each specimen was then subjected to bisulfite treatment using the EZ conversion kit (Zymo Research, Orange, CA, USA).

Quantitative methylation-specific polymerase chain reaction. Methylation of SGTP1 was analyzed by using the quantitative methylation-specific quantitative PCR (qMSP), which is a high-throughput quantitative methylation assay that combines fluorescence-based real-time PCR (TaqMan) technology with methylation-specific quantitative PCR. The qMSP was conducted with the Applied Biosystems 7500 RealTime PCR System (ABI7500; Life Technologies, Darmstadt, Germany). The primers were synthesized by Ruibo (Ruibo, Guangzhou, Guangdong, China). The primers and TaqMan probes are listed in Table 3. The PCR was performed under the following conditions: $94^{\circ} \mathrm{C}$ denaturation for $5 \mathrm{~min}, 20$ cycles of $95^{\circ} \mathrm{C}$ for $15 \mathrm{~s}, 66^{\circ} \mathrm{C}$ for $30 \mathrm{~s}$ followed by 30 cycles of denaturation at $95^{\circ} \mathrm{C}$ for $10 \mathrm{~s}$, annealing step at $58^{\circ} \mathrm{C}$ for 31 s. Each PCR was carried out in a 96-well plate composed of positive and negative controls. GAPDH was used as the endogenous reference to standardize plasma SGIP1 methylation levels. Three parallel auxiliary wells were used for each quantitative PCR reaction. The SGIP1 methylation levels for each sample was determined after normalization using the $2^{-\Delta}$ method relative to the internal reference GAPDH. CT calculation, $\triangle \mathrm{CT}=$ mean CT SGIP1 - mean CT GAPDH (the $\mathrm{CT}$ value was the threshold cycle for each sample). Afterward, SGIP1 methylation levels for each HCC patient (relative to healthy SGIP1 methylation levels) were expressed as fold change: Fold change $=2^{-\Delta \Delta C T}$, where $\Delta \Delta C T=(C T S G I P 1-$ CT GAPDH) - (CT normal - mean CT GAPDH normal).

Statistical analysis. All statistical analyses were performed by using SPSS 16 (SPSS; IBM, Chicago, IL, USA) software. Mann-Whitney $U$ test was used to determine differences in nonparametric variables. The optimal cut-off values were determined by simultaneously maximizing both the sensitivity, as well as the specificity, for detecting HCC using receiver-operating characteristics (ROC) curves. ROC curves were used to analyze diagnostic performance. Survival curves were adopted to analyze prognostic performance.

Overall survival (OS) was defined as the time between diagnosis and either death or the time of the last followup. Progression-free survival (PFS) was defined as the time from diagnosis to the time of progress or the last follow-up. Metastasis-free survival (MFS) was defined as the time from diagnosis to the time of metastasis or the last follow-up. Kaplan-Meier method and the log-rank test were adopted to analyze the survival time. A p-value $<0.05$ was considered statistically significant.

\section{Results}

Methylation status of SGIP1 in liver cancer tissues. We have studied 58 CpG sites through MALDI-TOF MS analysis. In the comparison of 16 cases of liver cancer tissue and normal adjacent tissues, the methylation of liver cancer tissues at the locus of SGIP1_1 and SGIP1_3; SGIP1_1CPG_15.16.17.18; 
20.21.22; 23.24; SGIP1_1CPG_25; SGIP1_1CPG_ 26; SGIP1_1CPG_27.28; and SGIP1_3CPG_4.5.6.7.8.9.10.11.12 were higher than those of normal adjacent tissues. The differences of these sites between the two groups were statistically significant, but not the other sites (Figure 1).
mRNA expression of SGIP1 and immunohistochemistry (IHC) in liver cancer tissues and normal adjacent tissues. To explore whether high methylation will affect gene expression, we have performed mRNA expression of 16 cases of liver cancer tissues and normal adjacent tissues. The

A

SGIP1-1

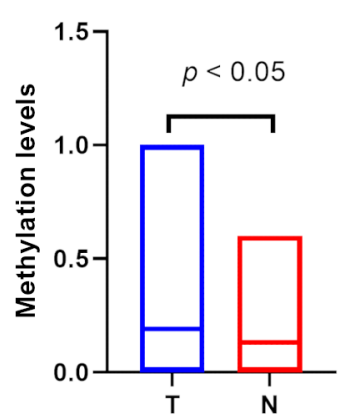

SGIP1-2

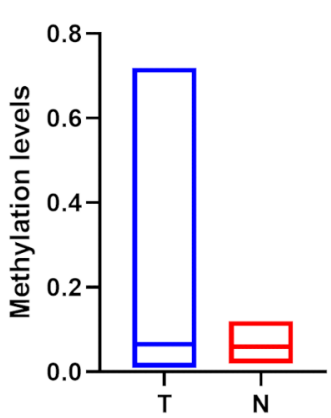

SGIP1-3

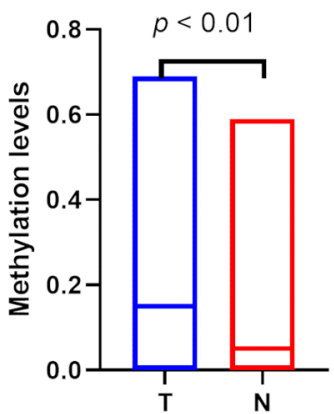

SGIP1-4

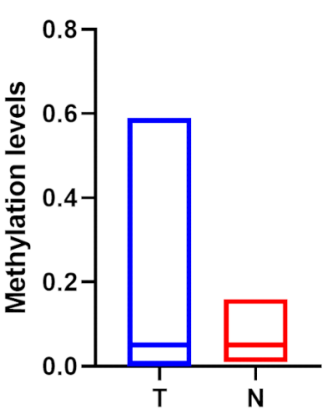

SGIP1-5

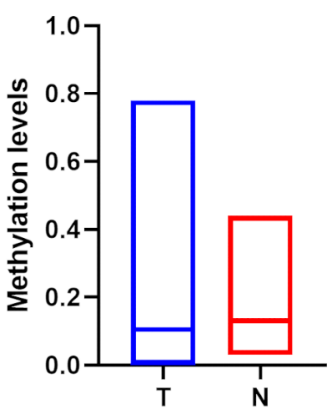

B

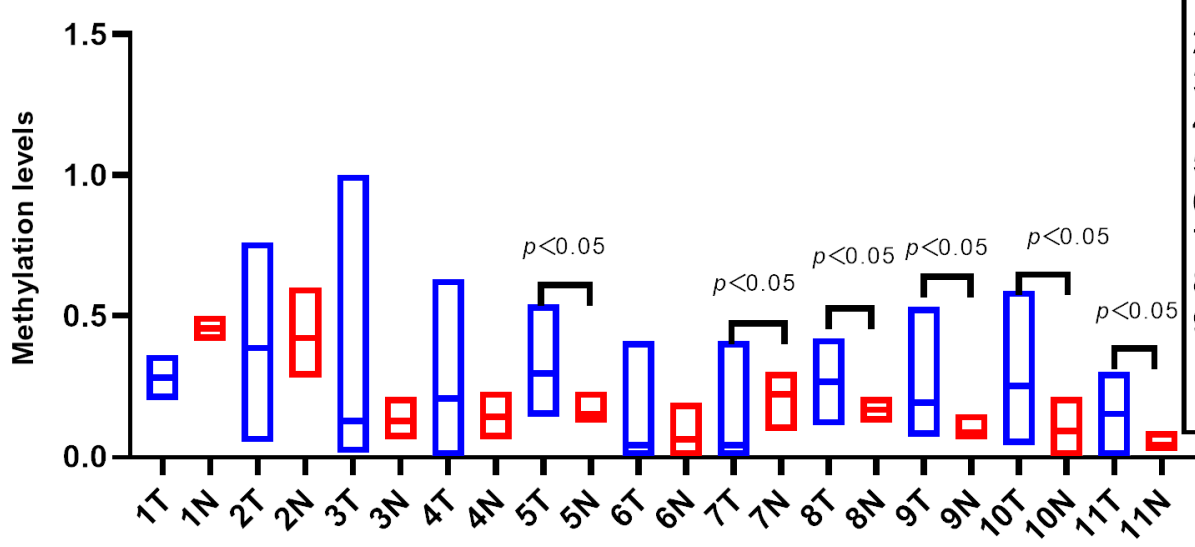

1.SGIP1-1CpG-1

2.SGIP1-1CpG-2.3.4.5

3.SGIP1-1CpG-6

4.SGIP1-1CpG-7.8

5.SGIP1-1CpG-15.16.17.18

6.SGIP1-1CpG-19

7.SGIP1-1CpG-20.21.22

8.SGIP1-1CpG-23.24

9.SGIP1-1CpG-25

10.SGIP1-1CpG-26

11.SGIP1-1CpG-27.28

C

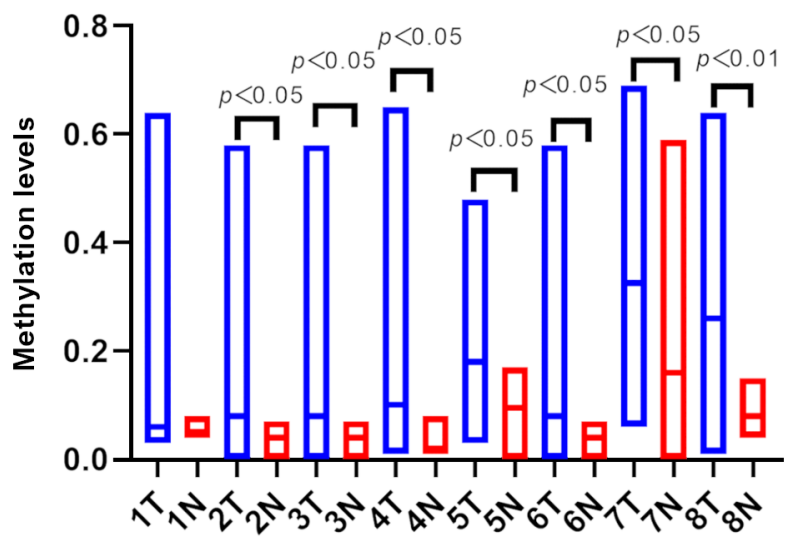

1.SGIP1-3-CpG-1

2.SGIP1-3-CpG-4

3.SGIP1-3-CpG-5

4.SGIP1-3-CpG-6

5.SGIP1-3-CpG-7

6.SGIP1-3-CpG-8

7.SGIP1-3-CpG-9.10

8.SGIP1-3-CPG-11.12

Figure 1. Methylation status of SGIP1 (A), SGIP1-1 (B), and SGIP1-3 (C) in liver cancer tissues and matched normal adjacent tissues. The methylation of liver cancer tissues at locus of SGIP1_1 and SGIP1_3 was higher than those of normal adjacent tissues (p<0.05); the methylation of liver cancer tissues at locus of SGIP1_1CPG_15.16.17.18,20.21.22,23.24,25,26,27.28 were higher than those of normal adjacent tissues (p<0.01); the methylation of liver cancer tissues at locus of SGIP1_3CPG_4.5.6.7,8.9.10,11.12 were higher than those of normal adjacent tissues (p<0.05). Abbreviations: T-liver cancer tissues; $\mathrm{N}$-normal adjacent tissues 

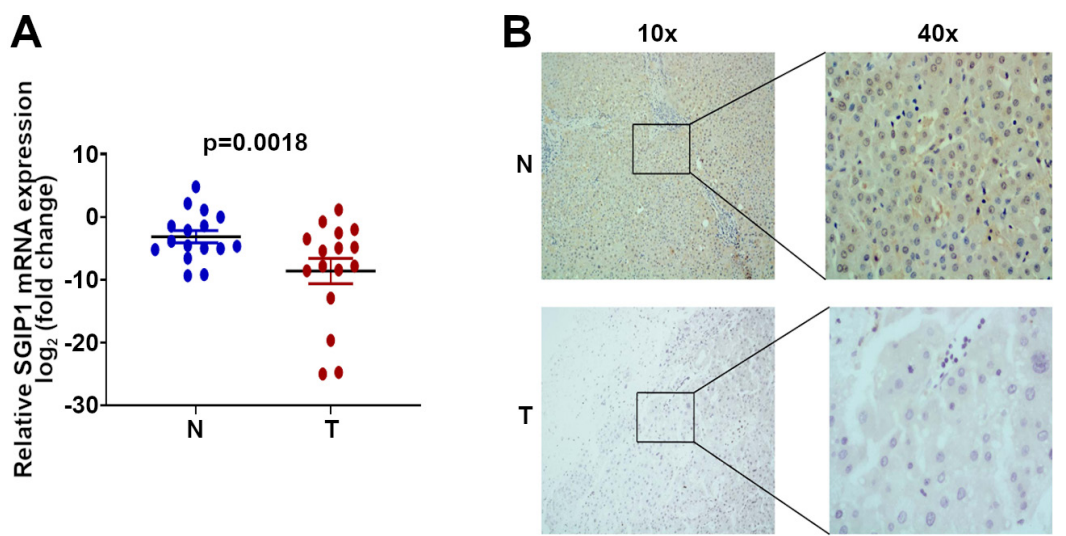

Figure 2. mRNA expression of SGIP1 and immunohistochemistry (IHC) in liver cancer tissues and normal adjacent tissues. A) The mRNA of SGIP1 in normal adjacent liver tissues was higher than liver cancer tissues $(\mathbf{p}<0.01)$. B) Protein levels of SGIP1 in normal liver tissues were higher than liver cancer tissues $(p<0.01)$. Abbreviations: T-liver cancer tissues; $N$-normal adjacent tissues

results showed that the mRNA of SGIP1 in normal adjacent liver tissues was higher than liver cancer tissues $(\mathrm{p}<0.01$, Figure 2A). Furthermore, protein expression was detected in liver cancer tissues and normal adjacent tissues via immunohistochemistry. The immunoreacted scores of SGIP1 in normal adjacent liver tissues $(3.81 \pm 1.328)(\bar{\chi} \pm s)$ were higher than liver cancer tissues $(2.44 \pm 0.964)(\mathrm{p}<0.01$, Figure $2 \mathrm{~B})$. These data suggest that high methylation may be responsible for the downregulation of mRNA and protein expression in liver cancer.

Levels of plasma SGIP1 methylation in different samples. The median methylation levels of plasma SGIP1 in $\mathrm{HC}, \mathrm{CHB}, \mathrm{LC}$, and HCC samples were $4(0.5,20)\left(\mathrm{Q}_{\mathrm{L}}, \mathrm{Q}_{\underline{U}}\right)$, $6.55 \times 10^{4}\left(0.5,1.97 \times 10^{5}\right), 6.55 \times 10^{4}\left(1.64 \times 10^{4}, 2.62 \times 10^{5}\right)$, and $2.62 \times 10^{5}\left(1.64 \times 10^{4}, 4.19 \times 10^{6}\right)$, respectively. The difference between $\mathrm{HC}$ and $\mathrm{CHB}, \mathrm{HC}$ and $\mathrm{LC}, \mathrm{HC}$ and $\mathrm{HCC}, \mathrm{CHB}$ or LC and HCC were statistically significant ( $<<0.01$, Figure 3$)$.

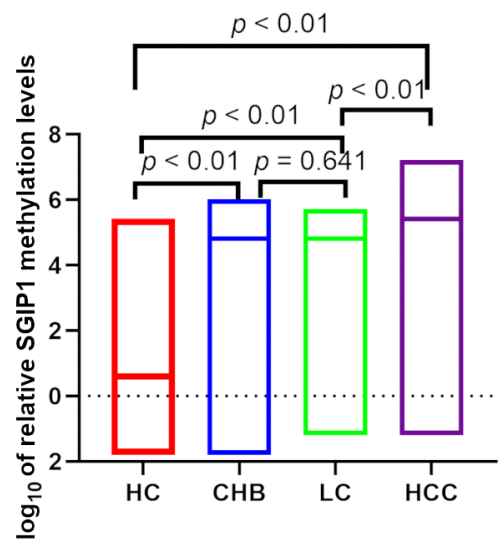

Figure 3. The levels of plasma SGIP1 methylation in different samples. The difference between healthy controls (HC) and chronic hepatitis B (CHB), HC and liver cirrhosis (LC), HC and hepatocellular carcinoma (HCC), CHB or LC and HCC were statistically significant $(\mathrm{p}<0.01)$.
The methylation levels of plasma SGIP1 in LC were slightly higher compared to $\mathrm{CHB}$ but the difference was not statistically significant $(\mathrm{p}=0.641)$.

Diagnostic value of plasma SGIP1 methylation and AFP in HCC. ROC curve was used to analyze the diagnostic value of SGIP1 gene methylation in distinguishing HCC from $\mathrm{HC}, \mathrm{CHB}$, and LC. The optimal threshold was selected based on the threshold of the maximum Jordanian index. As shown in Table 4 and Figure 4, SGIP1 gene methylation displayed a high diagnostic ability in discriminating HCC from $\mathrm{HC}$ with an AUC of 0.872 , with $85.3 \%$ sensitivity and $88 \%$ specificity. Meanwhile, the diagnostic ability of SGIP1 gene methylation in distinguishing HCC from CHB or LC resulted in a low sensitivity ( $43.4 \%$ and $43.4 \%$, respectively) and high specificity ( $97.8 \%$ and $100 \%$, respectively), with an AUC of 0.728 and 0.675 , respectively. The diagnostic ability of SGIP1 gene methylation in distinguishing HCC from non-HCC was similar to that in distinguishing HCC from CHB. When SGIP1 was combined with AFP25 (AFP $\geq 25$ ), it assisted in distinguishing between HCC and HCs by $95.3 \%$, and distinguishing HCC from benign liver diseases such as hepatitis and cirrhosis by $86 \%$, as shown in Supplementary Tables S1-S5.

Correlation with clinicopathologic parameters. SGIP1 methylation levels were higher in male patients compared to female patients, higher in T3 and T4 patients compared to $\mathrm{T} 1$ and T2 patients, higher in patients with distant metastasis compared to patients with no distant metastasis, and higher in III and IV patients compared to I and II patients. Furthermore, SGIP1 methylation levels in patients with tumor diameters greater than or equal to $5 \mathrm{~cm}$ were higher compared to patients with tumor diameters less than 5 $\mathrm{cm}$ and were higher in patients with abnormal AFP levels compared to patients with normal AFP levels. The differences mentioned above were statistically significant, except for the remaining clinical factors, as shown in Table 5. 

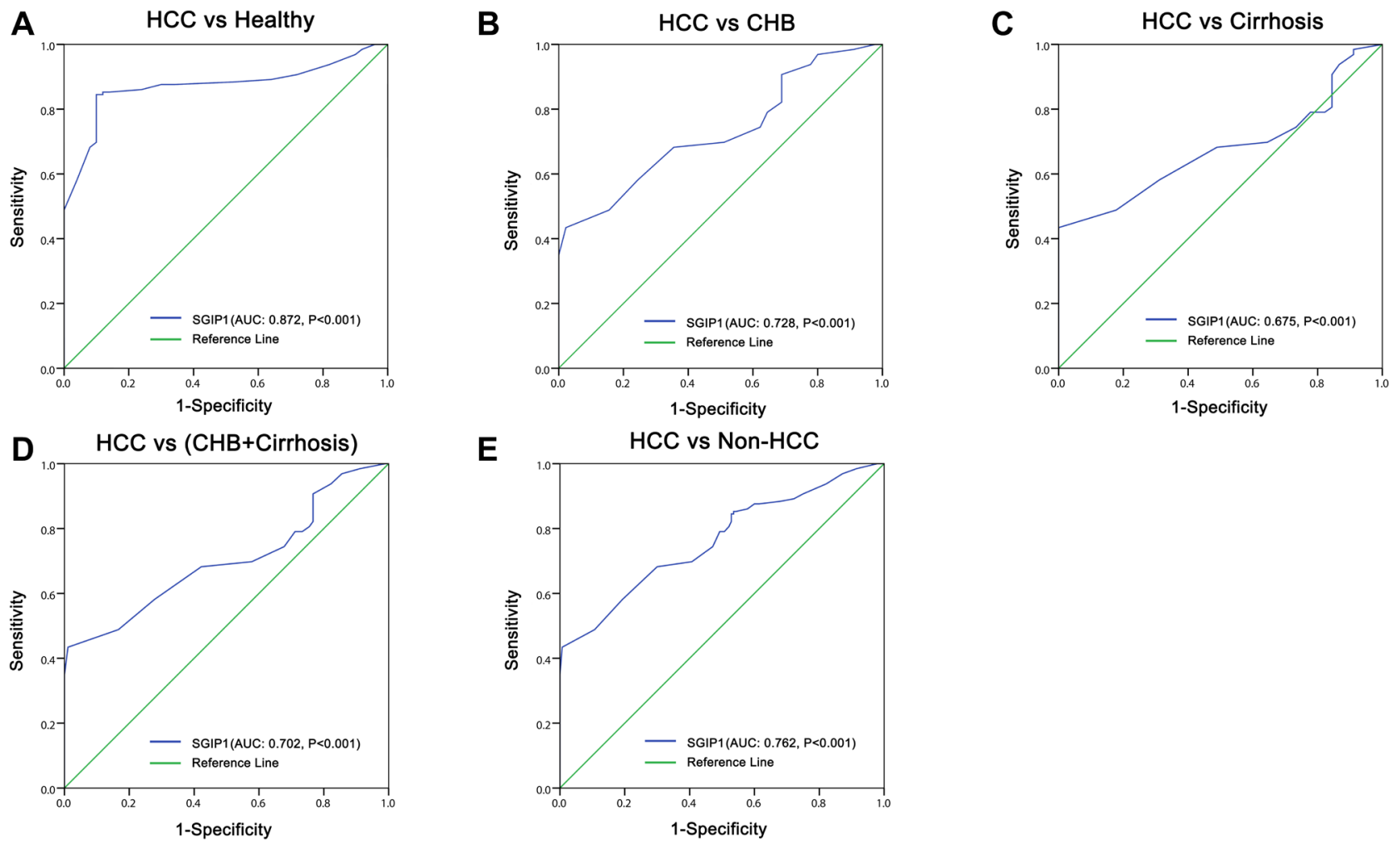

Figure 4. Diagnostic value of plasma SGIP1 methylation in HCC. A) SGIP1 gene methylation to discriminate patients with hepatocellular carcinoma (HCC) from healthy controls. The area under the curve (AUC) was 0.872 , with $85.3 \%$ sensitivity and $88 \%$ specificity. B) SGIP1 gene methylation to discriminate HCC from chronic hepatitis B (CHB). The AUC was 0.728 , with $43.4 \%$ sensitivity and $97.8 \%$ specificity. C) SGIP1 gene methylation to discriminate HCC from liver cirrhosis (LC). The AUC was 0.675 , with $43.4 \%$ sensitivity and $100 \%$ specificity. D) SGIP1 gene methylation to discriminate HCC from CHB and LC. The area under the curve (AUC) was 0.702 , with $43.4 \%$ sensitivity and $98.9 \%$ specificity. E) SGIP1 gene methylation to discriminate $\mathrm{HCC}$ from non-HCC $(\mathrm{CHB}+\mathrm{LC}+\mathrm{HC})$. The AUC was 0.762 , with $43.4 \%$ sensitivity and $99.3 \%$ specificity.

Table 4. Diagnostic value of SGIP1 methylation in distinguishing HCC in the different populations.

\begin{tabular}{|c|c|c|c|c|c|}
\hline \multirow{2}{*}{ Case vs. Control } & \multirow{2}{*}{ Cut off } & \multicolumn{4}{|c|}{ Performance } \\
\hline & & AUC (95\%) & Sensitivity (\%) & Specificity (\%) & p-value \\
\hline HCC vs. HC & 160 & $0.872(0.819-0.924)$ & 85.3 & 88 & $<0.001$ \\
\hline $\mathrm{HCC}$ vs. $\mathrm{CHB}$ & 786432 & $0.728(0.653-0.804)$ & 43.4 & 97.8 & $<0.001$ \\
\hline HCC vs. LC & 786432 & $0.640(0.525-0.755)$ & 43.4 & 100 & $<0.001$ \\
\hline $\mathrm{HCC}$ vs. $(\mathrm{CHB}+\mathrm{LC})$ & 786432 & $0.672(0.570-0.774)$ & 43.4 & 98.9 & $<0.001$ \\
\hline HCC vs. non-HCC & 786432 & $0.749(0.666-0.832)$ & 43.4 & 99.3 & $<0.001$ \\
\hline
\end{tabular}

Abbreviations: HCC-hepatocellular carcinoma; CHB-chronic hepatitis B; LC-liver cirrhosis; HC-healthy controls; non-HCC-(CHB+LC+HC)

Correlation with OS, PFS, and MFS. Based on the median plasma SGIP1 methylation levels in the 129 patients with liver cancer, patients were divided into the high-level group (> median) and low-level group ( $\leq$ median). There were 8 patients lost during follow-up, including 5 in the high-level group and 3 in the low-level group. The 1-year survival rate of patients in the high-level group was $71.5 \%$ and $85.6 \%$ in the low-level group. The difference was statistically significant $(p<0.01$, Figure $5 A)$. The one-year progression-free survival rate of patients in the high-level group was $37.1 \%$, while it was $55.5 \%$ for the low-level group ( $<<0.01$, Figure $5 B$ ). The one-year metastasis-free survival rate of patients in the highlevel group was $83.1 \%$, while it was $94.9 \%$ for the low-level group ( $\mathrm{p}<0.01$, Figure $5 \mathrm{C}$ ).

\section{Discussion}

SGIP1 has been reported to be involved in the occurrence and development of gastric and intestinal cancers [22, 23], through the Cancer Genome Atlas (TCGA) database, we found that SGIP1 methylation in liver cancer tissue is higher than that in normal liver tissue. Can SGIP1 methylation be 
used for the diagnosis of liver cancer? So, we carry out this research to explore it.

Our results demonstrated that the SGIP1 gene methylation levels were higher in $\mathrm{CHB}$ and LC patient samples compared to HC patient samples, while it was higher in HCC

Table 5. Correlations between plasma SGIP1 methylation and clinicopathological characteristics of the HCC patients.

\begin{tabular}{|c|c|c|c|}
\hline $\begin{array}{l}\text { Clinicopathological } \\
\text { factors }\end{array}$ & Cases & SGIP1 M $\left(\mathrm{Q}_{\mathrm{L}}, \mathrm{Q}_{\mathrm{U}}\right)$ & p-value \\
\hline \multicolumn{4}{|l|}{ Gender } \\
\hline Male & 112 & $5.24 \times 10^{5}\left(3.28 \times 10^{4}, 4.19 \times 10^{6}\right)$ & 0.035 \\
\hline Female & 17 & $3.28 \times 10^{4}\left(1.25,1.31 \times 10^{6}\right)$ & \\
\hline \multicolumn{4}{|l|}{ Age (years) } \\
\hline$\leq 51$ & 61 & $1.05 \times 10^{6}\left(3.28 \times 10^{4}, 4.20 \times 10^{6}\right)$ & 0.196 \\
\hline$>51$ & 68 & $2.62 \times 10^{5}\left(7.17 \times 10^{3}, 2.10 \times 10^{6}\right)$ & \\
\hline \multicolumn{4}{|l|}{$\mathrm{T}$} \\
\hline $\mathrm{T} 1+\mathrm{T} 2$ & 55 & $3.28 \times 10^{4}\left(2.56 \times 10^{2}, 2.62 \times 10^{5}\right)$ & $<0.001$ \\
\hline $\mathrm{T} 3+\mathrm{T} 4$ & 74 & $2.10 \times 10^{6}\left(2.62 \times 10^{5}, 4.19 \times 10^{6}\right)$ & \\
\hline \multicolumn{4}{|l|}{$\mathrm{N}$} \\
\hline N0 & 115 & $2.62 \times 10^{5}\left(1.64 \times 10^{4}, 2.10 \times 10^{6}\right)$ & 0.247 \\
\hline N1 & 14 & $3.15 \times 10^{6}\left(2.29 \times 10^{5}, 8.39 \times 10^{6}\right)$ & \\
\hline \multicolumn{4}{|c|}{ 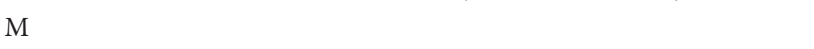 } \\
\hline M0 & 119 & $2.62 \times 10^{5}\left(1.64 \times 10^{4}, 2.10 \times 10^{6}\right)$ & $<0.001$ \\
\hline M1 & 10 & $4.19 \times 10^{6}\left(3.41 \times 10^{6}, 8.39 \times 10^{6}\right)$ & \\
\hline \multicolumn{4}{|l|}{ Clinical stage } \\
\hline I+II & 54 & $3.28 \times 10^{4}\left(2 \times 10^{2}, 3.28 \times 10^{5}\right)$ & $<0.001$ \\
\hline III+IV & 75 & $2.10 \times 10^{6}\left(2.62 \times 10^{5}, 4.19 \times 10^{6}\right)$ & \\
\hline \multicolumn{4}{|l|}{ Tumor size $(\mathrm{cm})$} \\
\hline$\geq 5$ & 81 & $1.05 \times 10^{6}\left(1.97 \times 10^{5}, 4.19 \times 10^{6}\right)$ & $<0.001$ \\
\hline$<5$ & 48 & $3.28 \times 10^{4}\left(20,2.62 \times 10^{5}\right)$ & \\
\hline \multicolumn{4}{|l|}{$\operatorname{AFP}(\mu \mathrm{g} / \mathrm{l})$} \\
\hline$\geq 25$ & 107 & $5.24 \times 10^{5}\left(3.28 \times 10^{4}, 4.19 \times 10^{6}\right)$ & 0.005 \\
\hline$<25$ & 22 & $2.46 \times 10^{4}\left(13,3.28 \times 10^{5}\right)$ & \\
\hline \multicolumn{4}{|l|}{$\operatorname{ALT}(\mathrm{U} / \mathrm{l})$} \\
\hline$\leq 40$ & 75 & $2.62 \times 10^{5}\left(1.28 \times 10^{3}, 2.10 \times 10^{6}\right)$ & 0.065 \\
\hline$>40$ & 54 & $5.24 \times 10^{5}\left(5.73 \times 10^{4}, 4.19 \times 10^{6}\right)$ & \\
\hline
\end{tabular}

Abbreviations: T-tumor; N-node; M-metastasis samples compared to CHB or LC samples. These differences were statistically significant. Plasma SGIP1 gene methylation has a high sensitivity for distinguishing HCC from HC, while it has a low sensitivity and high specificity for distinguishing HCC from CHB or LC. A combined diagnosis with AFP could improve its sensitivity. Plasma SGIP1 methylation in HCC is related to gender, tumor stage, tumor diameter, and AFP levels. Patients with higher SGIP1 methylation levels have worse overall survival, progression-free survival, and metastatic-free survival.

At present, there are many plasma or serum methylation testing methods for diagnosing HCC [26-30]. Some studies have compared HCC with normal healthy individuals [26], and a few others compared HCC with hepatitis and cirrhosis patients [27-29]. Do different comparison groups make differences in sensitivity and specificity? There are few studies that compared different groups at the same time [30]. In our study, the sensitivity of SGIP1 gene methylation in distinguishing HCC from normal individuals was $85.3 \%$, and $43.4 \%$ in distinguishing HCC from hepatitis or cirrhotic patients. This study, as well as the above study, indicated that different comparison groups could lead to different sensitivities.

In the studies that diagnose gene methylation in HCC, the sensitivity of most of the genes was not high, such as the sensitivity of RASSF1A was $52-73.3 \%[28,29]$, and GSTP1 was $17.4-38.7 \%[28,30]$. To increase the sensitivity, researchers have used a combination of multiple genes or with alpha fetoprotein (AFP). For example, Xu et al. have used a combination of 10 genes, and achieved a sensitivity of $85.7 \%$ and a specificity of $94.3 \%$ in distinguishing HCC from normal individuals [26]. In our study, when SGIP1 was combined with AFP25, it assisted in distinguishing between HCC and HCs by $95.3 \%$ and distinguishing HCC from benign liver diseases such as hepatitis and cirrhosis by $86 \%$. More importantly, the results of our study showed that different study groups could lead to different sensitivities. Practically, the highly sensitive study groups can be used as the detection group. For example, in the study conducted by
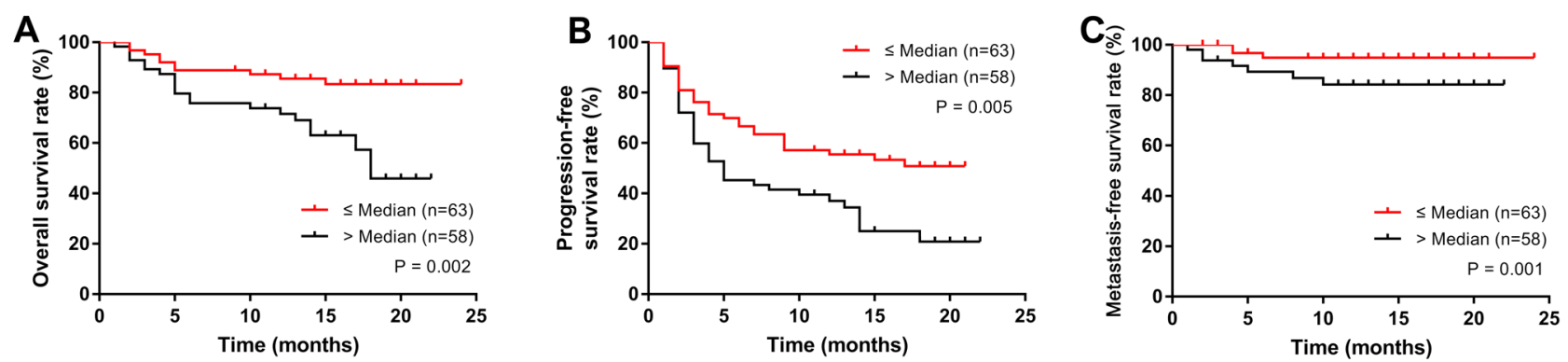

Figure 5. The relation between the levels of plasma SGIP1 methylation and survival. A) The 1-year survival rate of patients in the high-level (> median) group was $71.5 \%$ and $85.6 \%$ in the low-level $(\leq$ median) group $(p<0.01)$. B) The one-year progression-free survival rate of patients in the high-level $(>$ median) group was $37.1 \%$, while it was $55.5 \%$ for the low-level $(\leq$ median) group $(p<0.01)$. C) The one-year metastasis-free survival rate of patients in the high-level ( $>$ median) group was $83.1 \%$, while it was $94.9 \%$ for the low-level ( $\leq$ median) group $(p<0.01)$. 
Huang et al., APC demonstrated high sensitivity in distinguishing HCC from benign liver disease patients [30], and so it was used to screen HCC in patients with benign liver disease. While SGIP1 methylation was used to screen HCC in healthy people in our study.

There are several studies on the effect of gene methylation with regard to the survival of HCC. Xu et al. have demonstrated that they could effectively predict the prognosis of patients with HCC by combining the methylation of eight genes [26]. In our study, univariate analysis showed that HCC patients with high levels of SGIP1 gene methylation had worse OS, PFS, and metastatic-free survival. In multivariate analysis, SGIP1 gene methylation was shown to be an independent prognostic factor that affected metastatic-free survival. In addition, by analyzing the correlation between SGIP1 gene methylation and clinicopathological factors, the results showed that the plasma SGIP1 gene methylation was not only related to tumor stage and tumor burden but also related to distant metastasis. The possible reason for this is that the tumor locally invades the liver, and then the SGIP1 can enter the blood circulation system through local blood vessels, or the methylation of the SGIP1 gene promotes tumor proliferation and metastasis. SGIP1 gene methylation acts as an independent prognostic factor that affects metastatic-free survival, suggesting that patients with HCC can take different treatment options according to different levels of SGIP1 gene methylation. For example, patients with high methylation levels might require a more rigorous detection of distant metastases and need stronger systemic treatment.

There were several limitations to our study. First, this was a single-center study. Our results should be validated using larger multi-center patient cohorts. Second, the follow-up period in this study was short. Longer follow-up work should be performed to determine whether plasma SGIP1 methylation levels are related to prognosis.

In summary, our study demonstrated that plasma SGIP1 gene methylation levels had high sensitivity in distinguishing HCC from HC, while it had low sensitivity and high specificity in distinguishing HCC from CHB and LC. Diagnosis with a combination of AFP levels could improve its sensitivity. SGIP1 plasma methylation levels could be used as a non-invasive diagnostic method for HCC and need to be further validated using larger multi-center patient cohorts.

Supplementary information is available in the online version of the paper.

Acknowledgments: We would like to acknowledge the patients who participated in this study. We also gratefully acknowledge the assistance of the colleagues at State Key Laboratory of Oncology in South China and the Department of Liver Surgery in Sun Yat-sen University Cancer Center and professor Deng, Hong at The Third Affiliated Hospital of Sun Yat-sen University.

\section{References}

[1] BRAY F, FERLAY J, SOERJOMATARAM I, SIEGEL RL, TORRE LA et al. Global cancer statistics 2018: Globocan estimates of incidence and mortality worldwide for 36 cancers in 185 countries. CA Cancer J Clin 2018; 68: 394-424. https://doi.org/10.3322/caac.21492

[2] CAI Z, LIU Q. Understanding the global cancer statistics 2018: Implications for cancer control. Sci China Life Sci 2019. https://doi.org/10.1007/s11427-019-9816-1

[3] FENG RM, ZONG YN, CAO SM, XU RH. Current cancer situation in china: Good or bad news from the 2018 global cancer statistics? Cancer Commun (Lond) 2019; 39: 22. https://doi.org/10.1186/s40880-019-0368-6

[4] ALLEMANI C, MATSUDA T, DI CARLO V, HAREWOOD $\mathrm{R}$, MATZ $\mathrm{M}$ et al. Global surveillance of trends in cancer survival 2000-14 (concord-3): Analysis of individual records for 37513025 patients diagnosed with one of 18 cancers from 322 population-based registries in 71 countries. Lancet 2018; 391: 1023-1075. https://doi.org/10.1016/S01406736(17)33326-3

[5] GUI CH, BAEY S, D'CRUZ RT, SHELAT VG. Trans-arterial chemoembolization + radiofrequency ablation versus surgical resection in hepatocellular carcinoma - a metaanalysis. Eur J Surg Oncol 2020; 46: 763-771. https://doi. org/10.1016/j.ejso.2020.01.004

[6] TAMURA S, OKAMURA Y, SUGIURA T, ITO T, YAMAMOTO Y et al. A comparison of the outcomes between surgical resection and proton beam therapy for single primary hepatocellular carcinoma. Surg Today 2020; 50: 369-378. https://doi.org/10.1007/s00595-019-01888-5

[7] HUO YR, CHAN MV, CHAN C. Resection plus post-operative adjuvant transcatheter arterial chemoembolization (tace) compared with resection alone for hepatocellular carcinoma: A systematic review and meta-analysis. Cardiovasc Intervent Radiol 2020; 43: 572-586. https://doi.org/10.1007/ s00270-019-02392-6

[8] KIM JJ, MCFARLANE T, TULLY S, WONG WWL. Lenvatinib versus sorafenib as first-line treatment of unresectable hepatocellular carcinoma: A cost-utility analysis. Oncologist 2020; 25: e512-e519. https://doi.org/10.1634/theoncologist.2019-0501

[9] GOUTTE N, SOGNI P, BENDERSKY N, BARBARE JC, FALISSARD B et al. Geographical variations in incidence, management and survival of hepatocellular carcinoma in a western country. J Hepatol 2017; 66: 537-544. https://doi. org/10.1016/j.jhep.2016.10.015

[10] MANCEBO A, VARELA M, GONZALEZ-DIEGUEZ ML, NAVASCUES CA, CADAHIA $V$ et al. Incidence and risk factors associated with hepatocellular carcinoma surveillance failure. J Gastroenterol Hepatol 2018; 33: 1524-1529. https:// doi.org/10.1111/jgh.14108

[11] GE Y, MU W, BA Q, LI J, JIANG Y et al. Hepatocellular carcinoma-derived exosomes in organotropic metastasis, recurrence and early diagnosis application. Cancer Lett 2020; 477: 41-48. https://doi.org/10.1016/j.canlet.2020.02.003 
[12] BAKHEET AMH, ZHAO C, CHEN JN, ZHANG JY, HUANG JT et al. Improving pathological early diagnosis and differential biomarker value for hepatocellular carcinoma via rnascope technology. Hepatol Int 2020; 14: 96-104. https:// doi.org/10.1007/s12072-019-10006-z

[13] KOMOROWSKI AL, HSU CC, JULKA KD, VASAVADA B, LIN CC et al. Afp role in predicting recurrence of hepatocellular carcinoma after living donor liver transplantation in hcv patients. Neoplasma 2018; 65: 455-460. https://doi. org/10.4149/neo_2018_170315N184

[14] WU G, WU J, PAN X, LIU B, YAO Z et al. Racial disparities in alpha-fetoprotein testing and alpha-fetoprotein status associated with the diagnosis and outcome of hepatocellular carcinoma patients. Cancer Med 2019; 8: 6614-6623. https:// doi.org/10.1002/cam4.2549

[15] KIM MN, KIM BK, KIM SU, PARK JY, AHN SH et al. Longitudinal assessment of alpha-fetoprotein for early detection of hepatocellular carcinoma in patients with cirrhosis. Scand J Gastroenterol 2019; 54: 1283-1290. https://doi.org/10.1080 /00365521.2019.1673478

[16] LI L, CHEN J, XU W, DING X, WANG X et al. Clinical characteristics of hepatocellular carcinoma patients with normal serum alpha-fetoprotein level: A study of 112 consecutive cases. Asia Pac J Clin Oncol 2018; 14: e336-e340. https://doi. org/10.1111/ajco.12816

[17] SHE WH, CHAN ACY, CHEUNG TT, LO CM, CHOK KSH. Survival outcomes of liver transplantation for hepatocellular carcinoma in patients with normal, high and very high preoperative alpha-fetoprotein levels. World J Hepatol 2018; 10: 308-318. https://doi.org/10.4254/wjh.v10.i2.308

[18] SHIRAKI T, ISHIZUKA M, KUBOTA K, KATO M, MATSUMOTO $\mathrm{T}$ et al. An elevated neutrophil-to-lymphocyte ratio predicts a poor postoperative survival in primary hepatocellular carcinoma patients with a normal preoperative serum level of alpha-fetoprotein. Surg Today 2019; 49: 661669. https://doi.org/10.1007/s00595-019-01781-1

[19] ZHANG C, GE S, WANG J, JING XT, LI HL et al. Epigenomic profiling of DNA methylation for hepatocellular carcinoma diagnosis and prognosis prediction. J Gastroenterol Hepatol 2019; 34: 1869-1877. https://doi.org/10.1111/jgh.14694

[20] LI GX, DING ZY, WANG YW, LIU TT, CHEN WX et al. Integrative analysis of DNA methylation and gene expression identify a six epigenetic driver signature for predicting prognosis in hepatocellular carcinoma. J Cell Physiol 2019; 234: 11942-11950. https://doi.org/10.1002/jcp.27882
[21] ZHANG Y, FENG Y, XIN Y, LIU X. Sgip1 dimerizes via intermolecular disulfide bond in muhd domain during cellular endocytosis. Biochem Biophys Res Commun 2018; 505: 99-105. https://doi.org/10.1016/j.bbrc.2018.09.075

[22] BAE JH, KANG MJ, YANG KM, KIM TO, YI JM. Epigenetically silenced micrornas in gastric cancer: Functional analysis and identification of their target genes. Oncol Rep 2015; 34: 1017-1126. https://doi.org/10.3892/or.2015.4036

[23] LI JN, ZHAO L, WU J, WU B, YANG H et al. Differences in gene expression profiles and carcinogenesis pathways between colon and rectal cancer. J Dig Dis 2012; 13: 24-32. https://doi.org/10.1111/j.1751-2980.2011.00551.x

[24] CHANDRASHEKAR DS, BASHEL B, BALASUBRAMANYA SAH, CREIGHTON CJ, PONCE-RODRIGUEZ I et al. Ualcan: A portal for facilitating tumor subgroup gene expression and survival analyses. Neoplasia 2017; 19: 649-658. https://doi.org/10.1016/j.neo.2017.05.002

[25] TANG L, TAN YX, JIANG BG, PAN YF, LI SX et al. The prognostic significance and therapeutic potential of hedgehog signaling in intrahepatic cholangiocellular carcinoma. Clin Cancer Res 2013; 19: 2014-2024. https://doi. org/10.1158/1078-0432.CCR-12-0349

[26] XU RH, WEI W, KRAWCZYK M, WANG W, LUO H et al. Circulating tumour DNA methylation markers for diagnosis and prognosis of hepatocellular carcinoma. Nat Mater 2017; 16: 1155-1161. https://doi.org/10.1038/nmat4997

[27] TAO LP, FAN XP, FAN YC, ZHAO J, GAO S et al. Combined detection of insulin-like growth factor-binding protein 7 promoter methylation improves the diagnostic efficacy of afp in hepatitis b virus-associated hepatocellular carcinoma. Pathol Res Pract 2018; 214: 144-150. https://doi.org/10.1016/j. prp.2017.10.004

[28] DONG X, HOU Q, CHEN Y, WANG X. Diagnostic value of the methylation of multiple gene promoters in serum in hepatitis b virus-related hepatocellular carcinoma. Dis Markers 2017; 2017: 2929381. https://doi.org/10.1155/2017/2929381

[29] LIU XY, FAN YC, GAO S, ZHAO J, CHEN LY et al. Methylation of sox 1 and vim promoters in serum as potential biomarkers for hepatocellular carcinoma. Neoplasma 2017; 64: 745-753. https://doi.org/10.4149/neo_2017_513

[30] HUANG ZH, HU Y, HUA D, WU YY, SONG MX et al. Quantitative analysis of multiple methylated genes in plasma for the diagnosis and prognosis of hepatocellular carcinoma. Exp Mol Pathol 2011; 91: 702-707. https://doi.org/10.1016/j. yexmp.2011.08.004 